\title{
Flux transfer events at the magnetopause and in the ionosphere
}

Article

Published Version

Elphic, R. C., Lockwood, M., Cowley, S. W. H. and Sandholt, P. E. (1990) Flux transfer events at the magnetopause and in the ionosphere. Geophysical Research Letters, 17 (12). pp. 22412244. ISSN 0094-8276 doi:

https://doi.org/10.1029/GL017i012p02241 Available at https://centaur.reading.ac.uk/38855/

It is advisable to refer to the publisher's version if you intend to cite from the work. See Guidance on citing.

Published version at: http://dx.doi.org/10.1029/GL017i012p02241

To link to this article DOI: http://dx.doi.org/10.1029/GL017i012p02241

Publisher: American Geophysical Union

All outputs in CentAUR are protected by Intellectual Property Rights law, including copyright law. Copyright and IPR is retained by the creators or other copyright holders. Terms and conditions for use of this material are defined in the End User Agreement.

\section{www.reading.ac.uk/centaur}

\section{CentAUR}

Central Archive at the University of Reading 
Reading's research outputs online 


\title{
FLUX TRANSFER EVENTS AT THE MAGNETOPAUSE AND IN THE IONOSPHERE
}

\author{
R. C. Elphic
}

Los Alamos National Laboratory

M. Lockwood

Rutherford Appleton Laboratory and Blackett Laboratory, Imperial College

S. W. H. Cowley

Blackett Laboratory, Imperial College

P. E. Sandholt

Physics Department, University of Oslo

\begin{abstract}
On December 1, 1986 the ISEE 1 and 2 spacecraft pair passed through the dayside magnetopause at a location which mapped approximately to ionospheric field-line footpoints near the fields of view of the EISCAT radar and photometers and an all-sky camera on Svalbard. The magnetosheath magnetic field was southward and duskward at the time, and flux transfer events (FTEs) were observed at the ISEE location. At the same time, the EISCAT radar observed ionospheric flow bursts of up to $1 \mathrm{~km} \mathrm{~s}^{-1}$. The peak of each burst followed an FTE observation at ISEE by a few minutes. The bursts, each lasting ten or fifteen minutes, were comprised of first a westward then a poleward flow. An allsky camera at Ny Ålesund observed dayside auroral breakup forms during or shortly after the flow bursts, moving westward then poleward. While these flow bursts and associated dayside auroral forms have been previously reported in association with southward IMF orientations, this is the first observation of a direct link to FTEs at the magnetopause. On this occasion, the lower limit on the inferred potential associated with the FTEs is roughly $10 \mathrm{kV}$. Their inferred east-west extent in the ionosphere ranges between 700 and $1000 \mathrm{~km}$, corresponding to a $3-5 R_{E}$ local time extent at the average magnetopause.
\end{abstract}

\section{Introduction}

It is widely believed that magnetic reconnection occurs at the dayside magnetopause in both a quasi-steady and transient form, the latter producing "flux transfer events" or FTEs. Steady-state reconnection leads to global magnetospheric and ionospheric convection, but the precise effect of transient reconnection is less clear. Nevertheless, impulsive or transient reconnection at the magnetopause ought to produce some manifestation in the magnetosphere and ionosphere. Bolshakova and Troitskaya [1982], Glaßmeier et al. [1984], Lanzerotti et al. [1987] and Goertz et al. [1985] all searched for ground signatures of FTEs with ambiguous results.

Copyright 1990 by the American Geophysical Union.

Paper number 90GL02045

0094-8276/90/90GL-02045\$03.00
In an effort to capture the effects of FTEs both at the magnetopause and in the ionosphere simultaneously, a joint EISCAT/ISEE campaign was initiated in 1986 . This campaign called for enhanced tracking of the ISEE 1 and 2 spacecraft near the magnetopause for those periods when the EISCAT 'POLAR' radar experiment field of view was near the cusp. Various observational and operational constraints and problems limited the number of joint operation intervals to roughly five. Of these, FTEs were clearly seen at the magnetopause in one interval, 0800 - 1000 UT on 1 December, 1986. Neither ground activity nor FTEs were seen on the other occasions. Here we examine observations of FTEs at the magnetopause and related ionospheric and dayside auroral phenonomena as seen near the cusp footpoint by the EISCAT radar and all-sky cameras and photometers in Svalbard.

\section{Observations}

For this campaign the EISCAT radar used the 'Polar' beamswinging technique for obtaining two-dimensional ionospheric flow vectors in the neighborhood of the dayside cusp north of Troms $\varnothing$. The technique has been described in detail by Lockwood et al. [1989]. The basic cycle time is 5 minutes.

ISEE 2 was inbound in the early post-noon sector in the northern hemisphere and crossed the magnetopause at about 0925 UT at a position of $(8.43,3.29,5.08) R_{E}$ GSM. The left panel of Figure 1 shows the ISEE trajectory projected on the Y-Z GSM plane for a 30-minute period after ISEE crossed the magnetopause. Also shown are three traces of the Tsyganenko [1987] model magnetic field lines which pass through the trajectory, and the $\mathrm{Y}-\mathrm{Z}$ projections of the observed field orientation within the magnetosphere on this pass. The right panel shows the geographic placement of the center of the EISCAT radar 'POLAR' range gates 1 through 5, the Ny Alesund all-sky camera field of view, the meridian scanned by the photometers and the ISEE footpoints from 0940 to $1000 \mathrm{UT}$. The center of the EISCAT field of view is at roughly $75.0^{\circ}$, $13.0^{\circ}$ geographic, some $270 \mathrm{~km}$ west of the ISEE footpoint.

Figure 2 shows an overview of the ISEE 2 magnetic field data and the inferred electric potentials across the radar field of view associated with the flows for the period 0800 to 1000 UT on 1 December 1986. The field data are running $12 \mathrm{~s}$ 


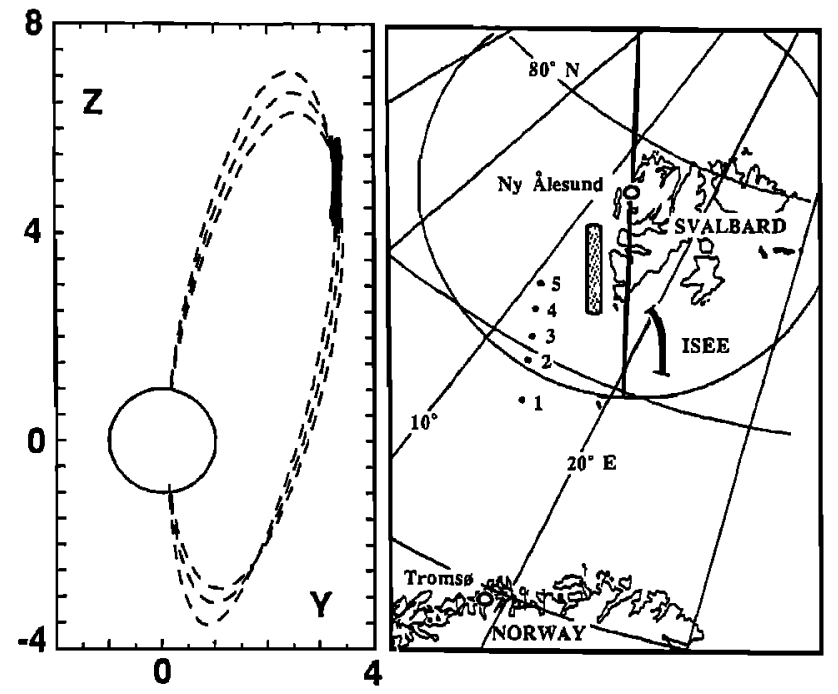

Fig. 1. (Left) View from the sun of the trajectory of ISEE 2 in GSM coordinates with observed magnetospheric field vectors just inside the magnetopause between 0930 and 1000 UT on 1 December, 1986. Also shown passing through the trajectory are three model magnetic field lines from Tsyganenko [1987]. (Right) Geographic locations of the EISCAT radar field of view, showing range gates 1 through 5 , and the field of view of the Ny Ảlesund all-sky-camera installation (large circle). Location of the persistent cusp/cleft arc is shown by the hatched region. The footpoints of ISEE 2 field lines between 0930 (northern-most point) and $1000 \mathrm{UT}$ (southern-most point) are shown by the thick trace to the east of the EISCAT field of view and the Ny Alesund magnetic meridian.

averages every $4 \mathrm{~s}$ in boundary normal coordinates. The L and $\mathrm{M}$ components are in the nominal magnetopause plane while the $\mathrm{N}$ component is normal to that plane. The normal is calculated assuming the magnetopause is a tangential discontinuity. The resulting $L$ and $N$ unit vectors are $(-0.442$, $0.019,0.897)$ and $(0.891,0.131,0.436)$ in GSM coordinates. The inferred normal is about $7^{\circ}$ off the average magnetopause normal direction at the ISEE 2 location. Minimum variance analysis yields a similar normal direction.

The data begin with ISEE 2 inbound in the magnetosheath. After 0806 UT the magnetosheath field was strongly duskward ( $40 \mathrm{nT})$ and southward. Using the canonical 10$n T$ peak-to-peak minimum $\mathrm{B}_{\mathrm{N}}$ amplitude and 1-minute minimum duration identification criteria, the first FTE occurs at 0845 UT (earlier $\mathrm{B}_{\mathrm{N}}$ activity around $0820 \mathrm{UT}$ does not meet the acceptance criteria). Another FTE is observed at 0904 UT. Thereafter, a long series of $\mathrm{B}_{\mathrm{N}}$ excursions are seen; those passing the selection criteria occur at 0911, 0914, 0926, 0931, 0937 and $0950 \mathrm{UT}$. In the midst of this interval, at $0917 \mathrm{UT}$, a $B_{L}$ spike is seen [Farrugia et al., 1988; Farrugia, 1989]. The magnetopause is crossed at $0925 \mathrm{UT}$, with a partial crossing later near 0936 UT.

The bottom panel of Figure 2 shows the north-south and east-west potential drops calculated from the $-\mathbf{V} \times \mathbf{B}$ electric field integrated over the radar field of view. For $\Phi_{\mathrm{NS}}$ the north-south electric field is integrated over the $200 \mathrm{~km}$ span of the first four range gates. $\Phi_{\mathrm{EW}}$ is derived from the east-west electric field at range gate four integrated over the $285 \mathrm{~km}$ sep-

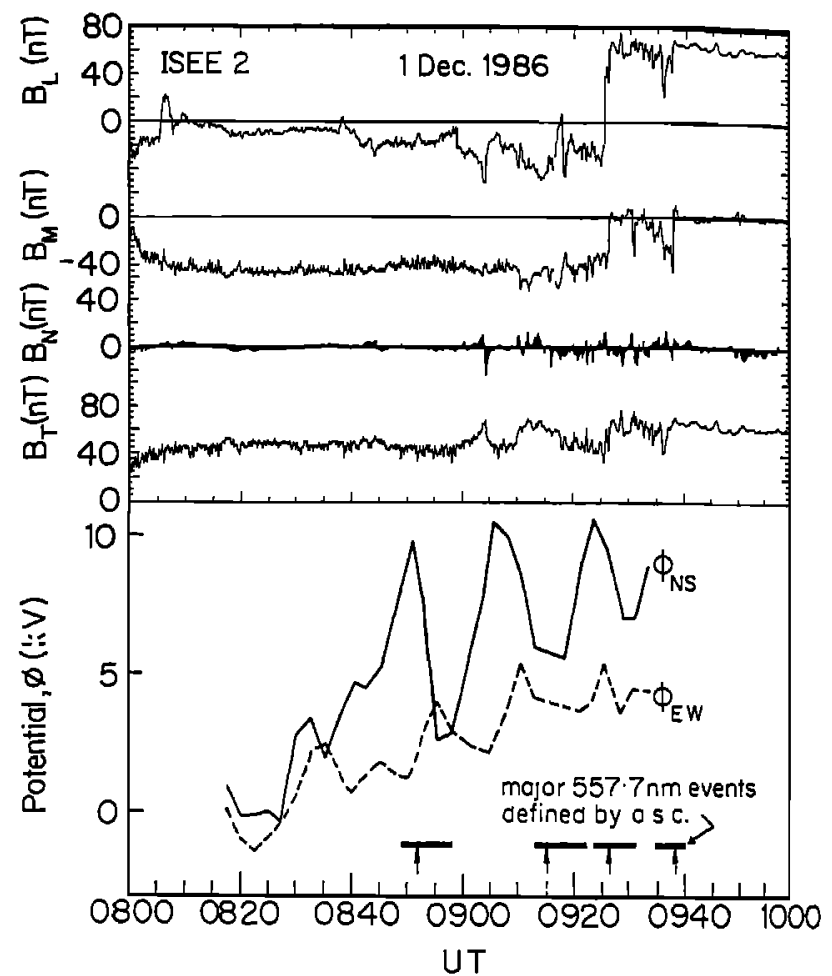

Fig. 2. Combined time series plot of the ISEE 2 magnetic field observations in boundary normal coordinates and inferred electric potential across the EISCAT field of view for the interval 0800 to 1000 UT on December 1, 1986. Horizontal bars at the bottom of the figure denote dayside auroral breakup events as seen at Ny Ålesund.

arating the two beam directions there, but normalized to a 200 $\mathrm{km}$ separation for comparison with $\Phi_{\mathrm{NS}}$. These values are essentially lower limits on the potentials since the plasma flow may have extended over a much broader region than just the radar field of view. Maxima in $\Phi_{\mathrm{NS}}$ are $3 \mathrm{kV}$ at $0832 \mathrm{UT}, 10$ $\mathrm{kV}$ at $0850 \mathrm{UT}, 10 \mathrm{kV}$ at $0907 \mathrm{UT}$ and $11 \mathrm{kV}$ at $0924 \mathrm{UT}$. Maxima in $\Phi_{\mathrm{EW}}$ follow those in $\Phi_{\mathrm{NS}}$ by roughly 2 minutes, but are smaller in magnitude. After the third $\Phi_{\text {Ns }}$ peak the potentials never drop back to their earlier low levels. The beginnings of a fifth $\Phi_{\mathrm{NS}}$ excursion is seen before the data end at 0934 UT.

In Figure 3 we focus on the ISEE $2 \mathrm{~B}_{\mathrm{L}}$ and $\mathrm{B}_{\mathrm{N}}$ components together with the northward and eastward flow components from the first four range gates from 0815 to 0945 UT. The highest flow speeds are seen at the poleward-most latitudes (range gate 4), but very similar flow behavior is also seen at the lower-latitude range gates. There is a westward swing in the low speed ( $\leq 400 \mathrm{~m} \mathrm{~s}^{-1}$ ) flows just before 0830 UT. A strong westward flow burst just before 0840 UT is seen only at gate 4; the lower latitude positions reflect the enhanced flow at about 0844 UT. The flow persists in a westward sense until $0851 \mathrm{UT}$, then swings northward. The next westward flow burst begins just before 0900 UT and turns more northward by 0907 UT. This flow persists until the next westward flow intensification at 0918 - 0922 UT.

Horizontal bars at the bottom of Figure 2 denote auroral breakup events seen by the Ny Ålesund $557.7 \mathrm{~nm}$ all-skycamera to the north and east of the EISCAT range. These 


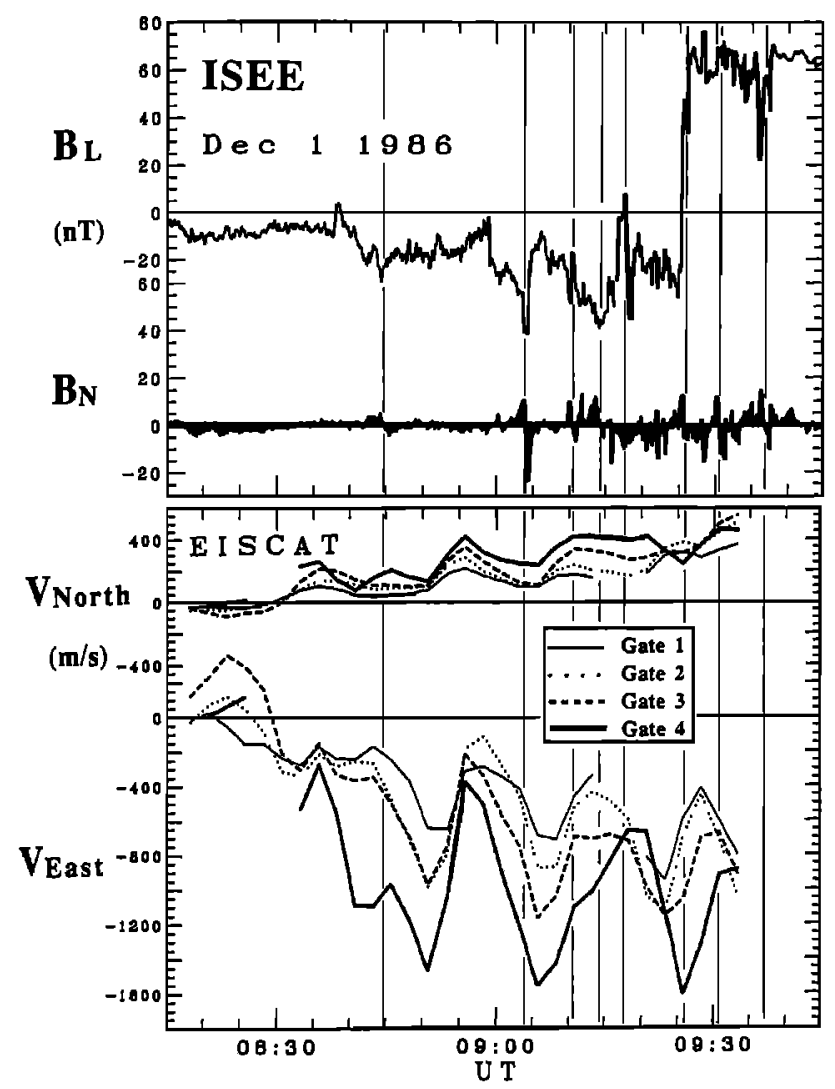

Fig. 3. Time series of the ISEE $B_{L}$ and $B_{N}$ components and EISCAT $V_{\text {North }}$ and $V_{\text {East }}$ flow components from range gates 1 through 4 for the interval 0815 to 0945 UT. Vertical lines denote FTEs and a $B_{L}$ spike at 0917 UT. Ionospheric flow bursts are coherent over all range gates in the interval.

events follow the peaks in $\Phi_{\mathrm{Ns}}$ and last between 4 and $8 \mathrm{~min}$ utes. We focus here on the second optical event centered at 0915 UT. Figure 4 shows Ny Allesund $630 \mathrm{~nm}$ photometer scans along the local meridian and four all-sky images of $557.7 \mathrm{~nm}$ intensities (represented as isophotic contours). The persistent cusp/cleft arc is seen well to the south of local zenith. The first $630 \mathrm{~nm}$ intensification for this event appears shortly before 0910 UT, just after the $\Phi_{\mathrm{NS}}$ peak at EISCAT. The intensity peak moves gradually northward and fades by 0915 UT. Meanwhile a new peak develops further south. A higher latitude peak brightens just before 0920 UT and subsequently merges with the lower latitude peak. The $557.7 \mathrm{~nm}$ all-sky images following the flow event at 0908 UT show an auroral form that brightens in the east at $0914 \mathrm{UT}$, subsequently moves to the west and stretches poleward at 0916 UT. By 0918 UT it is a very elongated east-west form with its westem-most edge also the most poleward. The $557.7 \mathrm{~nm}$ auroral forms reach far poleward of the persistent cusp/cleft arc.

\section{Discussion}

The observations demonstrate what appears to be a clear link between FTEs observed at the magnetopause and ionospheric flow bursts and dayside auroral breakup phenomena detected near the footpoint of the FTE field lines. Two westward flow bursts with center times at 0851 and 0907 UT closely follow

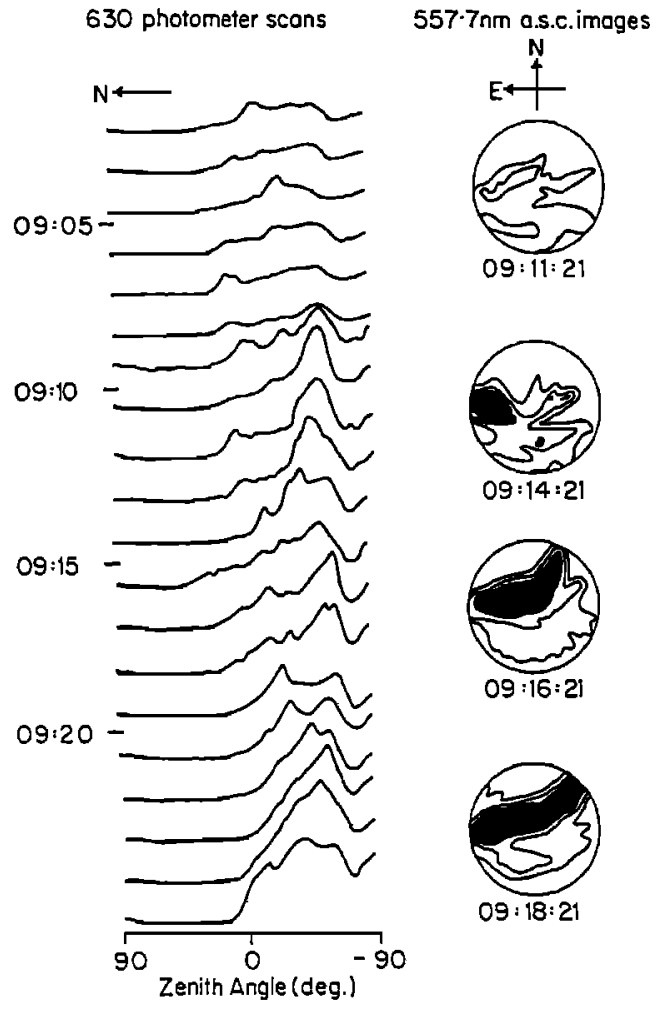

Fig. 4. (Left) Meridian scans of the $630 \mathrm{~nm}$ emissions over Ny Ålesund between roughly 0903 and 0925 UT. Note the appearance of a peak in emission at low latitudes just before 0910 UT. (Right) All-sky-camera images of $557.7 \mathrm{~nm}$ emissions above Ny Alesund, represented as isophotic contours. The peak emission is shaded black. Note that the auroral form begins in the east, moves west and then north as the event proceeds. This is the same motion as the westward then poleward flows observed by EISCAT.

two clear magnetosheath FTEs observed at 0845 and 0904 UT. A third flow burst at 0924 UT and the beginnings of a fourth just before $0934 \mathrm{UT}$ fall within a multiple-FTE period beginning at $0910 \mathrm{UT}$ and ending at about $0940 \mathrm{UT}$. There is also a $B_{L}$ spike (often seen associated with accelerated plasma flows in the near-magnetopause magnetosheath [Farrugia et al., 1988; Farrugia, 1989]) at 0917 UT, roughly five minutes before the westward flow peak seen at range gates 1 - 3. Major dayside auroral events seen in the all-sky-camera data from Ny Ålesund are associated with all three flow burst peaks. A fourth auroral event follows the beginnings of the fourth flow burst observed just before the end of EISCAT data acquisition and may be associated with the magnetospheric FTE at 0931 UT. The ionospheric flow and auroral sequences shown in Figures $2-4$ are very similar to those described by Sandholt et al. [1990] for other dayside breakup events.

The FTE activity after 0910 UT is problematic: $\mathrm{B}_{\mathrm{N}}$ signatures appear to occur with shorter durations and at shorter intervals than the 5-minute cycle time of the radar. Consequently we cannot expect to observe a one-to-one relationship between flow bursts and FTE signatures at this time. Nevertheless the increased FTE activity after 0910 UT may be reflected in the higher average values of ionospheric flow during 
this period. Indeed there is a general increase in both $\Phi_{\mathrm{NS}}$ and $\Phi_{\mathrm{EW}}$ (and in $\mathrm{V}_{\text {North }}$ and $\mathrm{V}_{\text {East }}$ at all range gates) with time as the average value of magnetosheath $\mathrm{B}_{\mathrm{L}}$ becomes increasingly negative between 0820 and $0925 \mathrm{UT}$.

The peaks of the ionospheric flow bursts follow the two magnetosheath FTEs by about 6 and $3( \pm 2.5)$ minutes, but the initial rise of the ionospheric flow bursts actually precedes these FTEs by 4 to $5( \pm 2.5)$ minutes. This is expected if the Alfvénic reconnection signal in the magnetosphere outraces the magnetosheath convective FTE signal: The magnetospheric Alfvénic signal, traveling from the subsolar magnetopause at $\sim 1000 \mathrm{~km} \mathrm{~s}^{-1}$, reaches the ionosphere in roughly $100 \mathrm{~s}$, while the convective signal, traveling at 100 to $200 \mathrm{~km} \mathrm{~s}^{-1}$, reaches the ISEE position in 200 to $400 \mathrm{~s}$. Thus the observed 240 - to 300 -s delay times are roughly consistent with the expected difference in Alfvénic and convective travel times.

We can use the observed northward and westward flows to estimate the respective north-south and east-west scale sizes of the ionospheric flow bursts. The northward bursts have average flow speeds of between 150 and $300 \mathrm{~m} \mathrm{~s}^{-1}$ and durations of about 10 minutes $(600 \mathrm{~s})$, yielding a characteristic northsouth scale size of 90 to $180 \mathrm{~km}$. The westward bursts range between 600 and $1000 \mathrm{~m} \mathrm{~s}^{-1}$ in average flow speed with durations between 10 and 15 minutes ( 600 to $900 \mathrm{~s}$ ); the resultant scale sizes range between 360 and $900 \mathrm{~km}$. Assuming the simplest mapping to the magnetopause with length varying as $\mathrm{B}^{-1 / 2}$, these scales become respectively 0.5 to $1.0 \mathrm{R}_{\mathrm{E}}$ and 1.8 to $4.5 \mathrm{R}_{\mathrm{E}}$ in the north-south and longitudinal (in local time along the magnetopause) directions, respectively.

\section{Conclusions}

We have presented observations of FTEs made by the ISEE 2 spacecraft at the dayside magnetopause and simultaneous EISCAT observations of ionospheric flow bursts and Ny Alesund observations of dayside auroral breakup events near the ISEE field line footpoints. The flow bursts were first westward, consistent with the sense of reconnection magnetic tension at the magnetopause [Gosling et al., 1990], then poleward as would be expected if reconnected flux tubes were convecting tailward with the solar wind. Each burst is associated with a north-south ionospheric potential whose lower limit is about $10 \mathrm{kV}$. Based on the magnitude and duration of the north-south and east-west components of the flow bursts we infer the scale sizes of these events to range between 100 and $200 \mathrm{~km}$ in the north-south dimension, and roughly 400 to $1000 \mathrm{~km}$ in the east-west dimension. Simple mapping of these lengths to the magnetopause yields an approximate inferred scale size of 0.5 to $1.0 \mathrm{R}_{\mathrm{E}}$ in the north-south dimension, and 2 to $5 \mathrm{R}_{\mathrm{E}}$ in the east-west dimension. Thus the local time extent of an FTE can be significantly larger than its north-south extent, in keeping with the model of FTEs by Southwood et al. [1988] and Scholer [1988].

Acknowledgments. We thank the director and staff of EISCAT for their assistance: EISCAT is supported by the research councils of France (CNRS), West Germany (MPG), Norway (NAVF), Sweden (NFR), Finland (SA) and the UK (SERC). We thank the ISEE project for expediting the joint
EISCAT/ISEE campaign. The optical observation campaign at Ny Ålesund and work done at the University of Oslo was supported by the Geophysics Laboratory, Hanscom Air Force Base, Massachusetts (H. C. Carlson), the Norwegian Polar Research Institute, and NAVF. ISEE data processing at UCLA was done under NASA grant NAG5-1067. We thank J. T. Gosling for useful comments. Work at Los Alamos was done under the auspices of the U. S. Department of Energy.

\section{References}

Bolshakova, O. V., and V. A. Troitskaya, Pulsed reconnection as a possible source of icp1 type pulsations, Geomagn. Aeron., 22, 723, 1982.

Farrugia, C. J., et al., Observations of flux transfer events, Adv. Space Res., 8, 249 - 258, 1988.

Farrugia, C. J., Observations of solar wind-magnetosphere coupling at the Earth's magnetopause, Phil. Trans. R. Soc. Lond., A 328, 57 - 77, 1989.

Glaßmeier, K.-H., et al., Pc 5 pulsations and their possible source mechanisms: A case study, J. Geophys., 55, 108 $119,1984$.

Goertz, C. K., et al., Observations of a possible ground signature of flux transfer events, J. Geophys. Res., 90, 4069, 1985.

Gosling, J. T., et al., Plasma flow reversals at the dayside magnetopause and the origin of asymmetric polar cap convection, J. Geophys. Res., 95, 8073, 1990.

Lanzerotti, L. J., et al., Ionosphere and ground-based response to field-aligned currents near the magnetosphere cusp regions, J. Geophys. Res., 92, 7739, 1987.

Lockwood, M., et al., Interplanetary magnetic field control of dayside auroral activity and magnetic flux transfer from the solar wind, Planet. Space Sci., 37, 1347, 1989.

Sandholt, P. E., et al., Midday auroral breakup events and related energy and momentum transfer from the magnetosheath, J. Geophys. Res., 95, 1039 - 1060, 1990.

Scholer, M., Magnetic flux transfer at the magnetopause based on single X-line bursty reconnection, Geophys. Res. Lett., $15,291,1988$.

Southwood, D. J., et al., What are flux transfer events?, Planet. Space Sci., 36, 503, 1988.

Tsyganenko, N. A., Global quantitative models of the geomagnetic field in the cislunar magnetosphere for different disturbance levels, Planet. Space Sci., 35, 1347, 1987.

S. W. H. Cowley, Blackett Laboratory, Imperial College, SW7 2BZ, London, U.K.

R. C. Elphic, Los Alamos National Laboratory, MS

D438, Los Alamos, New Mexico, 87545 USA

M. Lockwood, Rutherford Appleton Laboratory, Chilton, Didcot, Oxon OX11 OQX, U.K.

P. E. Sandholt, Physics Department, University of Osla, Box 1048 Blindern, 0316 Oslo 3, Norway

(Received: June 18, 1990

Revised: August 17, 1990

Accepted: August 28, 1990) 